\title{
Marginalization and Power in Living with and Researching Living with HIV
}

\begin{abstract}
Summary
This article takes its point of departure in a research project studying the psychosocial problems of living with HIV. The project was intended to participate in changing practices dealing with these problems. It became a project including many differently situated and intersecting personal and generalized perspectives. The article researches the development of the HIV project as a contribution to discussions related to Participatory Action Research and Practice Research. In mainstream approaches methodological indications are often presented as rules to follow in order to ensure the quality of the obtained knowledge. But situated historical and societal processes are involved in the effectuation of the HIV project, like they are in any other project. Researching the project heightens the awareness of the necessity of reflecting on situated and historical issues of power and marginalization and on the positions of the researcher in a given field of research. Methodological flexibility may also be necessary in order to encompass different perspectives. Such reflections and strategies are necessary precisely to ensure the development of knowledge and practice alike.
\end{abstract}

\section{Initiating a project}

In the late 80s a project studying the psychosocial aspects of living with HIV was initiated. A meeting was held by a Danish organization of lesbians and gay men. Hospital staff, NGOs, parents of people living with HIV, and several other interest groups participated. The general impression was that people living with HIV were frequently and "unnecessarily" hospitalized. And the general opinion was that many would be better off with a psycho-socially oriented type of care. During the meeting a small project group was organized to do something about what many of the participants regarded as a pressing problem. The project group was to design a project and to organize funds for research into the field. Furthermore it was to appoint a researcher, function as backing group for the research project, and eventually to take steps towards establishing a support facility. The status of the initiative was regarded as activist work.

The project group consisted of a medical doctor, a nurse from an HIV ward, a social worker at an HIV ward, a social pedagogue, and a member of an organization of people living with HIV. They obtained funds for what they planned to be the documentation of the need for a small collective residence, for physically weak and socially isolated people living with HIV. With the purpose of documenting the need for such residence, they agreed to employ a researcher. The contradiction apparent here is that these activists wanting to help others, and wanting to back up their intentions, 
and thus reaching their goal of a concrete alternative to current care practices, wished to employ someone to look into a problem to which they seemingly already knew the solution.

This type of approach to "research" seems to become more and more common. People working in social institutions register and develop situated perspectives on social and medical problems, to the solution of which they see a need to contribute. But since decision makers placed elsewhere in the bureaucracy of social work and health-care either do not see the problems or understand them differently, practitioners often have to document their perspectives. They may try to achieve "documentation" by employing "researchers" to "research" the already identified and often already defined problems. The start of the process of research in the HIV project points to the possible meanings of positioned and partial perspectives in research and in implementation of projects: Being involved in health-care and developing perspectives of living with HIV from their respective positions in health-care, most members of the group felt that research was needed to start "evidence based" change (a new "treatment") in practice.

The concept of "evidence based" involved here stems from medico-biological practices, in which it has primarily been used in relation to research based proofs of the effectiveness of medical treatment. The concepts and research practices related to it, although problematic, seem to be spreading to other purposes and other contexts of practice like the psychosocial. In this study, its use was related to "proving" the existence of a "known" complex of medico-psycho-social problems (Ekeland 1999). E.g. research was not primarily initiated to study possible problems and needs connected to living with HIV. It was mainly initiated to prove to the relevant authorities that a predefined problem existed.

Health care / hospital practitioners act as experts, and their situated personal perspectives relate to routines and discourses sometimes implying an objectification (often unknowingly and unwillingly) of patients. Aspects of the positioned perspectives of the group members enhanced mechanisms involved in the formulation of such "research projects", as in the initial one here. They "knew", what was in the best interest of the patients, e.g. they already "knew" the solution to the problem at hand.

\section{Re-searching methodology}

In the following I will discuss methodological issues evolving in the HIV project that were not quite as clear at the time of its implementation. The discussion is based on the paradigmatic approaches represented by authors such as Dreier and Holzkamp (Dreier 1997, 1999, 2002, Holzkamp 1995), and on the concept of situated participation in communities of practice (Lave and Wenger 1991). The approach represents a de-centered view of the subject. This means that the analytic approach to participatory aspects of subjectivity, such as different perspectives and actions, involves an analysis of the connections between them and the historical, locally situated possibilities and limitations for action in which they are developed. Actions are seen as having personal reasons that are aspects of participation in any, in time and space, given context of action. These reasons are embedded in trajectories of participation across different contexts in which subjects conduct their lives. Action is taken from positions constitutional to given contexts and co-determine possibilities and limitations of possible participation.

In a research process, it is then pertinent to ask in which ways the organizational aspects of the social contexts of action the researcher and other participants take part in co-create personal perspectives and standpoints, including blind spots of which we are not aware. Perspectives like the ones above, e.g. the use of the concept of "evidence based" practices, 
act so to speak on our behalf being generated and active "behind our backs". In their way of conceiving the project, the members of the group simply followed partial perspectives pertaining to positions basic to forms of action constitutive of health-care in its current historical structuration. These are constitutive forms of action that have evolved through the historical development of power in its institutions. As institutionalized perspectives and forms of action they are also more or less necessary preconditions pertaining to trajectories in and through these. The connected generalized perspectives, including concepts like "evidence based" practices, influence and may overrule other aspect of our personal perspectives.

\section{Change of research approach}

After interviewing several applicants for the researcher position, the project-group agreed on one candidate who completely changed the agenda. The appointed person is the author of this article. The explicit goal was changed from documenting a problem to which the answer was already given, to exploring the problems and needs for alternative psychosocial and medical support of people living with HIV, their friends and their relatives. It was to be an exploration of the perspectives of people living with HIV, their lovers, friends and other relatives, professionals in health care and professionals as well as activists from non-governmental organizations. The intention was to give voice to as many of the partial perspectives of agents in the field as possible.

The concretely formulated reasons for this choice are mostly unknown to the author of this article. But it may be assumed that the reformulation of the methodological and theoretical approach appealed to the members of the group for several and differing reasons depending on their personal perspectives. Some of these reasons were probably: 1) That the new approach seemed strategically and theoretically better argued in relation to the question at hand than the original proposal. This point would be important since the object of the project was to obtain funding for a support facility. 2) That it appealed to the perspectives of the group members generated in their positions as activists in the field of HIV. 3) And that it was more comprehensive of the complex constellation of different perspectives and positions of the group members themselves.

By altering the research approach, the project-group showed that generalized standpoints such as those generated in medical and social institutions are not static but changing. One of the reasons for this changeability is that participants in these institutions live their lives in and across different contexts. Thus they may develop different and at times conflicting perspectives on the same problems. These conflicting and partial perspectives may enrich each other. They may create possibilities for forming new and multi-faceted perspectives and personal standpoints that overcome generalized standpoints related to only one of the contexts of a personal participation. Another reason is that the institutions themselves are characterized by conflicting cooperation related to contradictions within their structurations and purposes, as well as by the many existing and possible positions within them.

\section{Partial Perspectives}

The concept of partial perspectives implies that participants in concrete situated practices, because of their position in such practices, have different possibilities for developing knowledge and experience with different aspects of such practices. No perspective is comprehensive, but all perspectives may contribute to developing knowledge about the specific practices. None of them, not even that of the researcher, is privileged (Dreier 1996, 1997, Danziger 1990). This conceptualization and related research practices are in conflict with 
the traditional conceptualization of "evidence" generated in research as neutral and objective, and with the positivist perspective that certain rules concerning research will result in neutral, objective evidence. Thus to think in partial perspectives was also partly a change from and in conflict with the original thinking of and goal designated by the project-group.

The members of the project-group did not only act from positions within medical or social institutions. They were also members of different activist groups working with people living with HIV, some were HIV-positive, and others had developed patient's perspectives through their lifelong use of the medical system. At the same time contradictions are and were at work within the medical system itself, among other things because it had to deal with a new group of well-formulated relatively young patients pressing for rights related to living with HIV. The members of the group were all more or less involved in promoting such rights, and some were even directly involved in political decision-making concerning the epidemic. Thus, aspects of their perspectives concerned with HIV were indeed partial, complex, multifaceted, and changing.

Because of this constellation of members of the group, their cooperation with a researcher open to the above-mentioned approach to research presented a unique possibility of a multi-perspective study of the meanings of living with HIV. A support facility which took into account the knowledge obtained by a multiple-perspective oriented study was made possible, in spite of the fact that the initial concept of the study was constructed in response to political and institutionalized administrative and bureaucratic demands for "evidence based" research and treatment.

\section{Power and possibilities of participation}

In the theoretic approach adopted in this article, power and marginalization are understood as embedded in possibilities and limitations of existing positions for participation in communities of action. The meanings of power and marginalization are situated and objectively existing as well as subjectively lived and understood.

In such a de-centered approach, personal perspectives, standpoints, and reasons for actions of concrete subjects are not sought "inside" theoretically individualized subjects, but are analyzed through their relations in and to the practices they participate in. Subjective action possibilities and reasons for action are concretely related to the complex, socio/material, and subjective organization of connections in and between the communities of practice in which personal participation takes place.

A specifically interesting point pertaining to positioned perspectives, power, and possibilities for participation in the project, concerned the representative of the organization of people living with HIV. He was the only person in the group not working in health-care or social work, but was a representative of future users of a facility (accidentally, the only formal representative of an organization). He mostly remained silent during group meetings, only speaking when asked. He was therefore at this point, as well as later, often marginalized in the formulation of the questions to be addressed, as well as in other decisions. Through this kind of marginalization and self-marginalization, the influence of a non-institutionalized and non-bureaucratic perspective and voice was weakened.

Also at an early stage a social-pedagogue participated in the group. She was working at an HIV hotline. Partially for this reason she represented a constellation of perspectives very different than the ones promoted by the partici- 
pants working in positions in health-care. The three hospital workers had initially agreed on the idea of a small collective habitation. The representative of people living with HIV had not taken a stand on the issue of the goal of the project, and the social-pedagogue was very interested in the idea of a hospice. It was an idea that all the others opposed, as they regarded a hospice as "the antechamber of death". The social-pedagogue voiced her opinions repeatedly. But these were often disregarded in the course of decision-making, and she was much criticized in her absence. She left the group after participating for a short time.

Thus, the possible perspectives of NGO psychosocial support systems, as well as the perspectives of people living with HIV, were partly marginalized because the dominant perspectives in the group were the very differently positioned perspectives of hospital workers. The generalized perspective of this type of medical institution had the prerequisites of becoming a very strong voice in the project.

Moreover, the group was influential in forming the "research design" and the practices involved in it. It was responsible for the implementation of the project, functioned as reference group for the researcher, who became a member. It was also a group that had many of the important connections in the field of research. It took initiatives concerning the selection of contexts of action included in the project, and concerning other aspects of cooperation connected to these. The distribution of responsibility and power between researcher and what was also to be called "the backinggroup" was never quite formalized.

In this period of the project, we see how certain positions have implied the possibility of more power in the process of participation than others, and through this also more influence in shaping the goals, methods, perspectives and future of the project. Members of the project-group appeared to be equals, in the sense that they participated in it as activ- ists. None of them were paid for the work done in relation to the project, and there were no formalized positions of power. In spite of this, some participants became very influential, while others were marginalized almost to the point of formal exclusion. Because of these processes of marginalization, a health-care perspective became dominant partly through the sheer power of number of participants.

In addition, the positivist medical paradigm with its tendency to objectification of its users as patients instead of an inclusion of their 1 . person perspectives is constitutive of dominant discourses in the health care sector. In spite of the activist positions of group members, and the NGO status of the project itself, such discourses also partially dominated the perspectives engendered in many of the group discussions and in the decisions taken by its members.

\section{Power and marginality across contexts}

Power in the project-group was mediated through the positions of participation members held in their job contexts and in politically oriented contexts, such as the national organization of gays and lesbians. Power relegated to participants in a community of practice like the backing-group, through the intersection of their different positions outside the group, and that of their possibilities for participation in the group, is not always easily identifiable as such. Therefore it will often be understood psychologically, e.g. as a result of personal traits or generalized group dynamics. In the common and emerging understandings of why some group members were marginalized and others held greater power in decision-making this played a role.

The influence of the medical doctor in the group is an example of the meanings of intersecting cross-contextuality. He held the posi- 
tion as informal leader of the group. One might have thought that being gay would weaken his possible influence. In other contexts of action this might have been the case. To be sexually involved with members of one's own sex is often seen as, and experienced as, entailing disadvantaged positions of marginalization. In this context it had quite a different meaning. An organization of gays and lesbians was the official applicant for the grant that financed the study. The organization was formally responsible for the implementation of the study. The medical doctor was a very well positioned member of this specific organization. It was implicitly in the group and explicitly in his position in this organization, that he had the possibility of sanctioning decisions and goals related to the project. The funding of the study, as well as the implementation of a possible support facility, were thus dependent on his active support. In the intersection of his positions, being gay meant empowerment, in particular since the organization had privileged positions in the governmental distribution of funds for HIV related projects. It constituted a lobby concerning political question related to policies on HIV. Several of its members had been employed as consultants in the national department of health. During the course of the study the project-group was directly accountable to the organization of gays and lesbians. The project-group acted as a support to the researcher, but also controlled researcher activities.

Furthermore, the nurse and social worker had both worked in hospitals for many years. Through their participation in these communities of practice, they were used to having to defer to decisions made by their superiors, who were medical doctors, and who were often men. So in a sense the social structuration of the group reflected the hospital hierarchy. Men in this hierarchy are most often found in administrative managerial positions and/or positions as medical doctors. Positions lower in this hierarchy require less education and are almost exclusively held by women. In direct extension, the representative of people living with HIV was in the group, partly positioned as a "patient", more to be taken care of than to be heard. The social pedagogue, an outsider to health-care institutions and a woman, was completely marginalized. Thus there was a general allocation of powerful positions to hospital staff and of marginal positions to others. This was strengthened by the fact that the nurse and the social worker, although women, held influential positions on HIV wards on whose cooperation the project also depended.

In this way, negotiations about possible positions and the influence of different partial perspectives and standpoints during the initial history of the project are acute examples of the meanings of power and marginalization as situated in concrete contexts of action and their intersections. Possibilities of influential participation in one community of action are often related to positions of power in others, and to the relative societal power of such communities. Here they are represented by the medical professions, and by their institutionalized practices and perspectives. But they are also represented by specific historical relations between an otherwise relatively marginal organization, i.e. the one of gays and lesbians, consultant and administrative positions relegated to its members, and governmental policies related to HIV. And, as the further re-examination of the project will show, this kind of intersections of positions not only co-determine possible participation in a group, the development of specific perspectives and the use of research methodologies. Since they co-determine decisions and thus adopted policies, they also co-determine the outcome of a project.

One could describe the scenario of this first period of the project in the following way: A group of people, with a complex combination of positions as professionals as well as NGO-activists, with a complexity of partly 
contradictory interests, intentions and official agendas, initiated a project which started out as an answer to bureaucratic demands. The group formulated and planned the project within this framework of practice. Through changes in perspectives realized in cooperation with the researcher chosen to carry out the study part of the project, it was reorganized into a multiperspective and participant-oriented research project. Consequently, the more NGO- and participant-based and research-oriented aspects of the plans formed by the group became dominant in the methodological approach.

As such it was the first major turning point in the project. But the following account will illustrate how the initial and inherent contradictions between a more institutional and bureaucratic oriented approach to the project, and a multi-perspective and participant-oriented project, will continue to be of importance in the understanding of decisions and events.

\section{Gender and power and marginalization}

Gendering categories and gendered ways of conducting daily life had bearings on the processes of power and marginalization in the HIV project. Haavind (1985), when discussing the relative domination of men over women as an active mechanism and a gendered aspect of the social constitution of practices, points to the fact that this is often overlooked or individualized. Ronkainen (Ronkainen 2001) coins the term "the rhetoric of genderless gender" to name the process in which gender inherent in social practices is hidden by a gender-neutral rhetoric of individual selves. The categories of male and female, as well as of homo- and heterosexual, gay and lesbian take on specific meanings related to the positions of power and marginalization held by the categorized subjects (Brown 1997, Pedersen 2001). In the HIV project situated relations between gays and lesbians on the one side and heterosexuals on the other, may also be viewed as relations of active, although relative, domination, just as may the relations between gay men and lesbians. But the meanings of gender categories as well as tacit gendered and gendering ways of dealing with positions in different communities of practice, was at the time neglected in the understanding of the development of the HIV project. This is often the case in research communities (Belenky, Clinchy, Goldberger and Tarule 1986, Haavind 2000).

Questions concerning these meanings will, apart from a few exemptions, not be addressed in this article. Meanwhile, the few exemptions, like the ones mentioned above, suggest that they may have had important consequences for the ongoing decision-making. I do not propose to explore the questions. I simply want to remind us that these are questions that ought to be included in research and in the analysis of research processes in general, instead of being relegated to the exclusivity and marginality of gender research. They are questions that concern "the independent integrity" of the world in which we conduct our lives and our research, as well as our "connectedness with this world" (Keller 1987). To include such questions in research is necessitated by what Keller calls "dynamic objectivity". But when including these questions one must bear in mind that the significance of gender categories are mediated through gendered and gendering positions and practices, as well as co-determined through trajectories of participation (Pedersen 2001).

\section{Methodological approaches}

Although the HIV project was inspired by Participatory Action Research (Foote Whyte 1991) and the tradition from which Practice Research springs (Dreier 1996, Nissen 1995, Nissen 2000) it did not follow these approaches stringently. One of the reasons was that it wasn't embedded in a collaborating research team. Being the only researcher among other participants in a process where several standpoints and interests were represented, and in 
which different paradigmatic approaches and professional procedures were at stake, keeping up stringent methodological reflections and strategies was difficult, at times even impossible. Furthermore the researcher was financed by severely limited project funds, subjected to rigid time limits and production demands, as well as isolated from the academic research community. The preconditions for in-depth methodological reflections were quite limiting $^{1}$. On the one hand, these and other restraints are well known to many researchers employed from project to project, making their living outside the academic research institutions, and are characteristic of much publicly financed research and evaluation. On the other hand, such problems will be endemic to much Practice Research. If the notions that practices are historical, locally situated and embodied (Lave and Wenger 1991) are to be taken seriously and used consistently, it means that not only individual subjects and the practices that are studied, but the whole process of a study will depend on and be entwined in possibilities and limitations of existing conditions.

A more mainstream, positivist oriented approach, represented by the initial research design created by the project-group, requires the planning of a well-delimited design. This is to be followed strictly through the whole study. It de-contextualizes perspectives of all participants, and privileges the perspectives of researchers. The intention is that results are to be objective in the sense that they are independent of concrete participating subjects (researchers as well as researched subjects) and the contexts in which they were engendered. According to this approach, following obligatory and standard rules ensures that a study fulfills the requirements necessary to be

1 The time at which this study was carried out was another reason for ideals in Practice Research not having been reflected and worked with in a consistent way. The elaboration of the concepts of Practice Research is of a more recent date. accepted as valid research in the research communities that ascribe to it. But such rules may become contradictory in and with a given practice and may always only be partly realized. And research practices and their differently positioned participants cannot be understood in a de-contextualized de-subjectified fashion. They cannot and should not be manipulated in a sovereign and objectifying manner by researchers (Montero 2002) according to rules inherent to specific research approaches, nor by other interested parties. This would be at the cost of action possibilities of other participants, and of the possibilities for obtaining knowledge (Martin 1996). These shortcomings, evident in the initial project design, were sought surmounted by adopting a more practice-oriented research approach.

Some of the ideas and intentions involved in the present approach to re-searching the HIV project consist of what Keller names

"Dynamic objectivity: A form of knowledge that
grants to the world around us its independent in-
tegrity but does so in a way that remains cognizant
of, indeed relies on, our (connectedness) with the
world" (Keller 1987, in Steiner 2000).

These ideas are akin to Practice Research in which research processes and the social practices being studied are understood as personal, situated, and concrete. In such an approach, indications concerning methodology are not to be understood as rigid rules. They are ideas to be reflected in relation to each concrete research project, and to be turned into changeable practices related to its specific conditions. Doing Practice Research, then, does not mean rigidly following a predefined design.

Thus, some of the intentions often stated in this and similar approaches are: To give as much room as possible for different, and differently situated perspectives, and for collective reflection; to facilitate a democratic distribution of power in defining issues to be 
researched; to encompass different perspectives, reflections and research strategies, while dealing with the given and changing conditions of the practices involved in a given study; to describe and analyze the conditions in relation to which the studied practices and their problems evolve and create conditions for practicing subjects. Thus, the paradigmatic approach adopted in this article views research itself as participation in diverse historical and situated communities of practice across time and space. Research is conducted in and into the everyday lives of subjects, and aims at obtaining knowledge from the diverse perspectives of all participants. Such research also aims at contributing directly to a studied field of practices in ways relevant to the participants. This is achieved by aiming at broadening possible scopes of action as well as connected perspectives and standpoints, while combining research with the development of practices.

\section{A mobile design}

The project was from the onset conceived as a combination of research and development of practices. From this intention followed that aspects of practices, and the consequences related to changes in practices, were already being reflected and acted on during the first period. In spite of this, the members understood the entire trajectory as divided into a clearly delimited research phase, followed by a just as clearly delimited phase of social action. It will become apparent why this delimitation could not be carried through in practice, and might not even have been desirable.

As suggested above, the first methodological intention was to do a survey study among potential users of a small collective housing project. But the original methodological plan was changed.

Several issues become central in researching the project: One issue is the paradigmatic approach used by the researcher, and the ensu- ing methodological practices during the course of the entire project. Another issue concerns the use of this paradigmatic approach, in which the intentions and understanding of methodological questions are radically different from a more positivist design. These two issues are interrelated. But let me start with the second.

The researcher had argued that certain questions and methods excluded from the original design could become important aspects in furthering the possibilities of obtaining funds for a potential support facility. Pointing to the chances of realizing an alternative to hospitalization was of course a very powerful argument, since the main reason given for initiating a study and developing knowledge of this field was an a priori assumption that such a need existed.

It was unusual that the organization of a support facility was preceded by a study. The project would illuminate some of the problems to which an eventual support facility might be an answer. A preliminary study was especially interesting in the case of a project on living with HIV, since the problems of living with HIV seemed to be connected to both the medical and the psychosocial sector, as well as to the relations between them. Thus, research in this field might eventually have implications far beyond questions pertaining to living with HIV.

A thorough and multi-perspective oriented study may obtain publicity, which was important for the further process of the project. It represented a unique chance to map some of the connections between health-care problems and psychosocial problems in living with HIV, and therefore to speak with greater authority on this question, as well as to generate knowledge that might benefit other possible initiatives.

So little was known of the field that it would be almost impossible to construct a meaningful survey, even disregarding problems concerning the kind of knowledge obtained with this method and its possible usefulness in rela- 
tion to the aims involved in the study (Danziger 1990 and 1997, Martin 1996, Ronkainen 1998).

If numerical results of surveys are usually effective in a political struggle for development in the health and social sectors, so are "real life" stories. Almost no such narratives had yet been voiced publicly. So doing research where presenting first person perspectives on and descriptions of living with HIV, seemed to make good strategic - as well as methodological - sense.

There were more reasons than these for why the proposals of the researcher became powerful in decisions taken by the project-group. The proposals related themselves to contradictory aspects of discourses on, and practices in research, that were current in the medically oriented paradigm, as well as in the psycho-social paradigm. In the end, the study was carried out as a combination of in-depth interviews and participation in relevant contexts, and a survey. Thus the proposals connected to perspectives held by all members of the backing-group were put into practice, and for a while made a partially shared perspective possible.

The other central issue mentioned above cannot be discussed independently of these arguments. As has become evident, most of the arguments for overruling the exclusivity of the survey method in this study were of a political, ethical or other nature, and not what is usually conceived of as scientific and methodological. Montero discusses how ethics and politics can and must be drawn out of the shadows in a revision of the paradigmatic foundations of psychological theories (Montero 2002). The claim in this article is that, when doing studies in social- and medical practices, these aspects of research are inseparable and in many ways constitute each other. The aim therefore cannot be to try to separate them, so to speak by force, but must be to understand in which ways they are interrelated, and therefore constitutive of each other. The methodological approach and procedures must consequently be a mobile, flexible, and reflected course of action dealing with the concrete situated practices and problems at hand. They should not follow rules which exclude possibilities for cooperation and the co-generation of knowledge. Some of the following examples from the project will illustrate this point further.

\section{Cooperation in a field of conflicting interests}

As mentioned above, the project touched on many interrelated, differently positioned, contradictory interests and perspectives in collaborative practices, and was itself an active part in these. Most of the cooperative relations which the researcher and the project-group participated in, were highly fragile, although not all voices in the field could be considered inherently fragile. This was the background for the necessity of differentiating the ways of studying it. It suggests that the more contradictory the studied practices are, the more it becomes necessary that researchers, in order to capture different perspectives, cooperate in flexible ways with agents in the field.

Issues pertaining to HIV and AIDS were then controversial and of a quite recent date. Sexuality and lifestyles, especially questions concerning men having sex with men, were focal points. Another issue was the not quite recognized contradictory interests between the medical community and the psychosocial community, as well as the ensuing battles for powerful positions within and between these. Yet another issue was the contradictory perspectives represented by NGOs (among which were organizations of users of the public systems), governmental and more local public institutions. Contradictions in perspectives and interests were accentuated because the aim of the project was to detect problems in the support systems, and to point at alternative possibilities for support. Apart from making weaknesses in 
existing institutions visible, this would mean receiving some of the limited funds earmarked for prevention and care concerning HIV and AIDS, e.g. competing with other agents. In this sense all relations established in order to implement the project were fragile, just as was the case of cooperative efforts organized in relation to one of the major HIV wards.

It was agreed that interviews with patients, participatory observations and a survey were to be carried out here. But these were not carried out. The reasons for this were multiple and interwoven. At first it seemed motivated by a newspaper interview that had been authorized by persons working on the ward. In this interview, the researcher had presented the project. But its headline, authored by the editor, had described all people living with HIV as helpless victims. The head of the ward made the project-group responsible for this. Later it turned out that there was a conflict of interest within the ward. It was rooted in the efforts of powerfully positioned employees to obtain funds for another support system. The people behind this project saw other initiatives, and especially the one in question here, as competition for recognition and funds. As such, the project seemed to be a possible threat to their own project, and ultimately to the prestige and funding of their ward.

Competition for recognition, e.g. for influence and necessary funds, turned out to be endemic to, and a constant threat to, cooperative relations during the development of the project. The HIV epidemic had caused the release of large amounts of funds for research and new support systems. But the field was already in need of funding and highly competitive. It was one in which individual projects and their participants were struggling for recognition, career trajectories, and sometimes for sheer survival. Axel (2002) points to cooperation in communities of practice as being conflicting, and to these conflicts as being necessary preconditions for change and development, although they may also inhibit development. This also goes for cooperation between differently positioned participants in Practice Research and related projects. It is and must be a continuous concern in these kinds of studies.

\section{Fragile perspectives and voices}

The perspectives of gay men were, at the onset of the project, seen as the most fragile perspectives. At the time they represented the vast majority of people living with HIV. The voices were seen as fragile in that they were perspectives of people understood as weakened by disease, and discriminated against like anybody living with HIV. The resulting expectation was that it would be difficult to obtain contact with such participants, and sometimes even that one should refrain from trying to ask them to participate. But they were important voices because the intention of the project was to capture first-person perspectives on social problems in living with HIV.

Additionally, the question of gay men arose as a third issue in cooperative conflicts with the HIV ward mentioned earlier. It turned out that a central figure at this ward considered these men and their organizations as a threat to his work with HIV. He was quoted voicing his perspective in the following way at a meeting with funding authorities: "No money should be given to a residential facility. Gay men have already received enough". A "residential facility", would not have been open exclusively to gay men. But the remark mirrored a prevalent view, namely that HIV was a homosexual disease, and that the organizations of gays and lesbians were much too powerful in the struggle for funding.

The remark also illustrates a further issue that was sometimes overlooked by the researcher of the HIV project. Its implications were most often outside the sphere of participation and influence of the researcher, as 
well as of the backing-group, and of others supporting the project. The remark illustrates, like the position of the medical doctor in the project-group, that voices are often privileged across contexts. Powerful positions in political contexts and/or in the medical sector created possibilities of influence in most of the relevant contexts of action of the field of the project. People holding such positions were and are in general not only especially influential in their primary positions. Their voices become privileged within more and broader fields of practice. They may marginalize and even silence relevant voices and interests connected to positions that are less central in the specific field of practice or in other fields.

Reversely, the project also showed that many people involved in work related to HIV, and hospital staff specifically, often experienced themselves as marginalized when faced with an active group of people/patients. They were not used to having to negotiate with such groups. The relative power involved in their usual possibilities for participation was being questioned through the voicing and collective actions pertaining to living with HIV, and relating sexually to other men. Projects that were not explicitly and exclusively aimed at other groups were perceived as being exclusively for homosexuals. This problem shows how the experience of marginalization is related to the positions of various participants, in relation to the shared objects of action, and as such also to their positions in relation to research projects.

How to deal with one's position is often a pressing question for people having sexual relationships with members of their own sex. During this study it implied a very pertinent methodological issue. Having to interview hospital staff, people living with HIV, NGO personnel, and others, the researcher, being open about being a participant in the gay and lesbian communities, made a difference. She experienced that introducing herself as a knowl- edgeable participant to gay men co-created an interview context that allowed many themes to be talked about which would otherwise not have been talked about. Having experienced discrimination within as well as outside hospitals, these men were cautious about whom they spoke to about what. Often, their perspectives on being gay and living with HIV were something they only wished to discuss with members of the gay and lesbian community, and they felt that only these would be able understand and sympathize with it.

Similarly, discriminatory generalizations about "homosexual men", voiced by hospital staff and others, would have remained unspoken had they known about the participation of the researcher in the gay and lesbian communities. But the knowledge about different perspectives and conflicting practices, due partially to the gay and lesbian/heterosexual controversies, and obtained through this subterfuge, was of great importance in understanding the issues and problems involved in creating alternatives to hospitalization. The notions and ideals of democratic participation and transparency implied in Practice Research were challenged by the manipulations implied in this selective use of strategies of transparency as opposed to passing as heterosexual. But demands for or unquestioned ideals of transparency in a research process such as this one presumes that all participants have equal access to participation e.g. to power. Discussions of ethics in psychosocial studies are rarely concerned with this problem.

An example of the necessity of awareness of the meanings of marginalization and of consciously choosing research strategies inclusive of these meanings (as well as in the planning of a prospective support facility), especially on the part of the researcher, was that for people living with HIV to use a residential arrangement placed in a rural area was more or less out of the question. Outside of very few major cities, the marginalization of both 
people living with HIV and of gay men, was simply too consistent. Another example was that taking up residence in an accommodation for people living with HIV was not seen as an option at all by most heterosexual men, since it seemed equivalent to being stigmatized as a homosexual.

\section{Access to knowledge}

"Invisibility" related to the marginalization of people of the gay community living with HIV actualized the question of access to knowledge during the course of the project. It was related to researching everyday lives and took on varying meanings in the research process itself.

In the paradigmatic approaches represented in this article, when you plan to illuminate certain aspects of a research question, you usually choose to observe, interview and participate in other ways in the practices of people that you assume can co-create the most relevant knowledge. This means that you try to cooperate with persons and combinations of persons who have different partial perspectives, and which you expect will give you the best possible insight into the field. Depending on the object of the study, the researcher will have more or less influence on the selection of whom to cooperate with. In some cases like this one, where many possible participants could be said to choose "invisibility", this aspect of control of the selection of participants is almost impossible. Many participants were not open about being gay, nor were they open about living with HIV and AIDS, nor about being their relatives. Actually, problems of "invisibility" in this study point to the more general fact that the idea, that researchers have the power to single-handedly select their collaborators according to specific rules, and are able to obtain total control over their roads of access to knowledge, is a megalomaniac fantasy. It is a goal left over from positivist rules of research design. The idea that only the knowledge obtained through the design controlled by the researcher alone, the data gathered through the implementation of this design and evaluated solely by researchers, is valid, is connected to this approach to psychosocial studies.

The process of working with HIV clarified how little control one had and most often has. Simultaneously this provided important knowledge on living with HIV. "Invisibility" was active in different ways. In order to interview people living with HIV, connections were obtained through people who were in daily contact with them. These were hospital staff, activists from NGOs, or friends. Even though the backing-group had many such contacts, potential cooperators were reluctant. This reluctance, not exclusively based on fear of discrimination, was even active in the motivation of the people who had the possibilities of recruiting them. Many nurses were very worried about asking patients. They thought it might jeopardize their relationships with them, also that they were too physically ill, too psychologically fragile. They did not want to intrude upon their privacy, including outing them, by asking for their participation. All this obviously reflected the specific positions of responsibility for care that nurses have in relation to "their patients" as they often called them. The consequence of "invisibility" was that interviewees were initially "selected" solely because it was possible to obtain contact with them.

But the possibilities of achieving contact augmented. Rumors about the project spread. One of the rumors was that this was the first study that was actually relevant for people living with HIV, since it was aimed at including their own perspectives and at creating new living and care facilities. Much research was being done in the field, but the study uncovered that very little seemed meaningful to people living with HIV. Thus the initial lack of en- 
thusiasm towards participation was not only due to the wish for "invisibility", as it had been assumed. The above mentioned hospital ward withdrew from cooperation for reasons that were not necessarily in the best interest of the patients. But the patients themselves, informed through other channels, became gradually more and more active in contacting the project, involved in participation, and, as a result, in shaping the project and its outcomes.

The recruiting of participants in a study is closely connected to the question of relevance with regard to positioned interests in possible outcomes of a study. Concrete aspects of recruiting possibilities and processes are in themselves sources of information that form a relevant part of any analysis i.e. reveal overarching historical dynamics.

In the case of the HIV project they illuminated differences in the perspectives and interests between some hospital employees and many of the potential users. People employed in institutions like the health-care sector had difficulties seeing the need for other kinds of support than the one the health-care institutions offered. Some were even against the implementation of other facilities for fear of competition for the limited funds. Recruiting conditions in this case meant that mainly the hospital wards and employees sympathetic to and interested in the creation of new support systems and gay men acted as informants. Thus, many of the results of the study were characterized not primarily by systems/bureaucratic perspectives, but by perspectives representing concrete lived problems of being HIV-positive. The evolving methodology of the project had also allowed for this, both in what concerned the mobility of the design, allowing subjects with marginalized voices to be heard, and through the ways in which they were interviewed and cooperated with.

\section{Positioned perspectives on a report}

In the following I will exemplify how some of the different ways the issues described in the project report were understood by differently positioned agents in the field. Knowledge about this was obtained through informal conversations with different agents throughout the whole process of working with the project, e.g. through presence at one of the major hospital wards, participation in the gay community, and contacts with other interest groups, as well as through more formal talks related to being a member of relevant committees and networks. Furthermore, the project report was sent for comments to all interviewees and other key persons. This knowledge is illustrative of the contradictory perspectives participants held. They were connected to their relatively central and powerful or relatively marginal positions in relation to the project and to the fields of practice as such. This knowledge also touches on the issues of democracy versus bureaucracy.

The report described and analyzed the problems, needs and wishes of possible users of new support systems, some of which were residential, others not. Apart from people living with HIV and their organizations, this description had included voices of employees from the public health and social services, as well as NGOs, relatives and friends. The question of the need for new support systems, and for which kinds, was central to all chapters of the report. But each chapter sought to discuss the matter from the perspectives of the different positions in the communities of practice related to living with HIV.

Noteworthy was that the chapter describing the perspectives and standpoints of relatives (biological families) and friends was the shortest. It was also the one most criticized by the informants themselves. Especially the 
biological families (parents and siblings) were poorly represented. Obtaining contact with them had been very difficult. Most were living "invisibly" in what connected them to HIV. Some had no contact with their sons and daughters, brothers and sisters, many in a state of helpless grief, and some had wide-ranging responsibilities and tasks related to the illness of their relatives. In addition, there was almost no organized help available to them.

Relatives are often overlooked in health and social systems, in this case more so than in most, because of the stigmatizing character of the disease. The negligence in representing the perspectives of this group was reflected in the place they were given in the research process and in the report. Several biological relatives also criticized that their own problems and needs for support were poorly understood within as well as outside the report.

However, one group of "relatives" was well represented. It was the gay and lesbian friends and lovers of people living with HIV. But there was lack of clarity about the meanings of the concepts of "relatives and family" for many gays and lesbians. They were often constituted by their relationships in the gay community.

Additionally, to say that they were well represented, is a statement in need of modification. Their voiced perspectives were often intersected with otherwise positioned aspects of voices because several perspectives were represented by one person. Many were living with HIV as well as having lovers and friends who were also HIV-positive, were active in an NGO and/or working in the public health systems. Which perspectives they were actually voicing became unclear. This was not taken into account in the analysis. So the meanings of perspectives generated by being participants with many different positions across contexts of action, e.g. the meanings generated by what could be called "intersectionality", were not analyzed precisely enough. This is an example of a research issue mentioned above: the con- sequences of perspectives and therefore voices being developed across contexts. These voices and aspects of them may be privileged across contexts.

Re-examining the perspectives, it seems that this kind of intersectionality often resulted in voices critical of the established institutions, and pointing to the necessity for changing and broadening support systems. There seemed to be a tendency for the aspects of voices that were developed through participation in the conduct of everyday life with HIV, to question or even overrule the generalized institutional aspects of perspectives that they might otherwise have represented. This is an interesting example of how personal perspectives are developed across contexts. Personal experience in the conduct of everyday life may contribute to modify or even overrule aspects of acquired and otherwise more powerful generalized perspectives. Here a participant oriented and relative democratic perspective was developed at the cost of the more institutionalized and bureaucratic one. Thus, the participant perspective again seems well-represented in the project and the report.

The responses of the medical community to the report were complex. Some medical researchers tried to invalidate the conclusions. They argued that the methodology employed was not scientifically correct, as it did not fulfill the criteria of positivist conceptions of objectivity. This argument was related to different, but subjective, ways of dealing with competition inherent in the character of existing and limited possibilities for career trajectories within the medical establishment. Other parts of the medical community used the report in educational programs, and even others suggested continued research along the same lines and supported its recommendations. That these uses seemingly expressed an opposition to the mainstream perspectives on science within the medical establishment does not mean that 
they were not also related to the opportunities situated there. But many doctors, nurses and other hospital staff were, because of their cooperation with people living with HIV or for other reasons in their personal life trajectories, genuinely interested in and actively engaged in furthering non-medical support systems. The limitations of the structuration, goals and routines of hospital communities often made them feel helpless in their very efforts to be of help to patients.

It should be added that the organizational gap in cooperation between the social sector and the health-care sector was highlighted through conflicts concerning initiatives towards practical change suggested by knowledge obtained through the study. Competition between the sectors for influence, funding and possible career trajectories was related to taking part in new initiatives. For this and other reasons, cooperation was fraught with possible conflicts of perspectives and interests. Although answers to the problems described in the report involved both sectors, no one suggested cooperation between them.

This was the second important turning point in what can be seen as the conflict between democratic and participant oriented tendencies, and institution oriented and bureaucratic tendencies in the project. From being a center of attention in both sectors, the work of the project-group as well as the initiatives suggested by the report were often marginalized in ensuing debates. It was partly a consequence of the knowledge presented in the report, favoring perspectives of marginalized participants such as less powerful hospital workers, NGO members, individual people living with HIV, and their families. But it was equally a consequence of contradictions between the presented knowledge and the intersecting cross-contextual aspects of interests of powerful bureaucratic positions and personal perspectives.

To start significant initiatives in the process of changing the support system of people living with HIV, the group then had to rely on its own resources and to look for allies outside the established institutional worlds.

\section{Creating a support facility}

The project - with its mobile design - involved uncovering many diverse and hitherto not formulated aspects of living with HIV. Thus it broadened the range of knowledge about possible practices of living with HIV. It also broadened the views on different new and necessary support networks. Moreover, the project implied and entailed social action in creating preconditions for the implementation of suggestions presented by the study. As a result, a facility was established. This was to become a third turning point in the conflict between democratic, participant oriented tendencies and institution oriented and bureaucratic tendencies.

The facility was at first conceived as a realization of the ideas suggested by the study. The house in question was to be a center for many forms of support, recreational, and political activities, in which its inhabitants as well as others, in the different communities of practice relating to the epidemic may participate.

The importance of organizing a support facility with influence delegated to all interested parties was clear, since the intention was the empowerment of people living with HIV. Therefore one idea was to organize a board of trustees, in which the interested parties were all represented. Also, because of the possible reduction of control over one's concerns often implied in the exclusive focus on care, care was not to be the only or even central focus. The facility was to offer as diverse possibilities for empowering the process of living with HIV as the perspectives presented in the study had indicated. Central to this was that there were to be very few rules and regulations, but many possibilities for and support of self-determination. Organizing the facility was a long 
and complex activity with many contradictory interests at play and ensuing conflicts, in which power and marginalization, already at work through the whole project, became more prominent.

As an example, before the facility itself was initiated, there were conflicts within the backing-group which resulted in the leaving of the current and second representative of the organization of people living with HIV. His clearly voiced opinion had been that the practices of the project should be empowerment-oriented. He did not think that the group in the process of establishing the facility was including his standpoints. Care-oriented and institution-based and -oriented perspectives where becoming more predominant, as concrete plans for a facility and its implementation were becoming the main activity of the group. Here practices that were well known to the hospital employees were in focus. In the conflicts of the decision-making process, their positions of relative power in other contexts became more influential than earlier, when there were less conflicts.

Needs of potential users of a facility, as well as the results of a study, can be interpreted in different ways, depending on whose positions and personal perspectives they are seen from. Personal perspectives and standpoints developed within these evolve through personal trajectories of participation in different contexts of action across time and space. The standpoints here and elsewhere represent personal ways of dealing with personal and positioned perspectives, possibilities, limitations and contradictions, and ones own concerns in these trajectories (Dreier 1997, 1999). These contexts may seem separate, but they are in fact connected in two ways. The first way is that they, as a whole, make up the trajectory of the individual subject. The second is that these seemingly separate contexts, are local and interconnected communities of practices integrated in overarching structurations of society.
They are as such related to the structurations of these practices. In order to be able coordinate and direct her or his actions in and through the diverse communities of practice, the subject develops a generalized personal standpoint as an aspect of his or her participation. This became apparent when a new representative of the organization of people living with HIV joined the group.

\section{Marginalization of perspectives}

Through the marginalization of the existing representative of people living with HIV, their general marginalization was enhanced in the group. The new representative was someone with a much more institution-oriented and bureaucratic standpoint. This might have been related to the activist organizations becoming more established. But it may also have been related to differences in employment background, as well as in personal experiences with the progression of the disease, of the two consecutive representatives. The latter had a tendency not to identify with possible users of a facility, but to categorize them as patients to be subjected to care, excluding himself from this category. This smoothed his cooperation with the eventually elected board of trusties, of which he became a member. His standpoints did in essence not vary much from theirs, mainly representing institutionalized perspectives. There had been competition for the limited seats on this board. The members turned out to be the more institution- and bureaucracy-oriented of the candidates. Possibly partly because representatives of activist organizations, unaccustomed to and often not interested in bureaucratic positions of power, had not realized the importance of membership and had not competed for it.

I will point to a few more eloquent facts concerning marginalization of the participantoriented perspectives and practices related to 
the cross-contextual meanings of positions of power.

An employee of the HIV ward which had stopped cooperating with the project-group during the "research period" obtained an important position on the board of trustees. Most important decisions relating to the everyday practices of the facility were relegated to, and effectuated by, the board of trustees. It was also the administrative body that hired employees and activists, and decided on who was to be referred to the facility and on what grounds. Many people admitted were patients of the above-mentioned ward, often people very much in need of basic physical care. In complete opposition to the initial plans, the focus of everyday practices bore resemblances to those of a nursing home. The organization of the facility reflected the classical hierarchy of many medical systems supplemented with volunteers. Its daily routines were organized around the care of relatively disabled patients. These were by then the main target group of the facility, and were left little to say about how the place was run.

Subsequently, many potential users of the facility, who had supported its realization, and had been in favor of a multi-activity center, refused to use it. Some even withdrew their support officially. Many activists did the same.

Pursuing the concept of "dynamic objectivity” (Keller 1987) doing research means participating in, and tracing and following processes of cooperation that are most often not regarded as relevant aspects of research endeavors. Actually, in most psychosocial research, they are more or less consciously excluded, even at times for the purpose of what is regarded as a necessary scientific objectivity.

In this project, conflicts between different communities of practice within the field partly hidden during previous processes flared up during the implementation of the results of the study. Visibility of differences and contradic- tory practices, which from the start had been endemic to the project, were consequently enhanced. These were crucial for the understanding of the contexts that were being studied. Important aspects of researched practices often only become visible in and through the changing of these practices.

In the HIV project, lack of knowledge about and understanding of perspectives and conduct of daily lives of potential users resulted in the implementation of a facility that was only directed at a minor part of the community whose wishes it was meant to address. The facility created was no real alternative to institutionalized support facilities. It ended up being in many ways indistinguishable from other bureaucratically conceived facilities. As re-searching the HIV project indicates, the reasons for this are to be found in the ways sociopolitical systems have a tendency to reproduce themselves. Positions of power in communities of practice organized by overarching aspects of society, and the personal perspectives, standpoints and trajectories developed as aspects of participation in these communities, contribute to this.

\section{Final remarks}

Many diversely positioned participants in the project represented different and seemingly contradictory aspects of generalized perspectives and standpoints. This multiplicity involved contradictory agendas and strategies linked to and developed through societal conditions for participation. It contributed to shaping the scopes of action of people living with HIV, as well the different activities aimed at supporting them. One example of this are the relations between professionals, professions and institutions within the health and the social sectors. Because of the limited financial possibilities in the field, they were in competition for funding, recognition, and career positions. They conducted their 
respective research and support projects with disconnected, (blindly) situated perspectives and conflicting paradigms. The lives of people living with HIV were conducted - although full of contradictions and conflicts - as continuous trajectories, while the institutions and other more powerful agents co-created separate contexts and perspectives pertaining to their lives (Højholt 2001).

Cooperation concerning research, new projects, and social action became a driving force behind the development of communities of practice. But because of conflicts of interests, positioned power, and processes of marginalization inherent in the field, necessary cooperation also inhibited possibilities for development. Production of knowledge in the universities was hardly included at all and neither was there any cooperation between the backing-group, the researcher and university researchers. Researchers mainly worked in separate communities; this characterizes much development research and many evaluation projects, to the detriment of research in the separate research communities.

In the HIV project, marginalization took on diverse, and, from a researcher's perspective, unexpected shapes. It was active in different seemingly independent life trajectories of people living with HIV, professionals, activists, friends and relatives. Some of the marginalization processes seemed to be connected to the double marginalization of gay men and of living with HIV. But the different meanings of these aspects of marginalization were mediated through positions of power in different professions, institutions, and their related research possibilities. Fragile voices and fragile cooperative relations became powerful, and some more marginalized. Some powerfully positioned voices became more powerful, and some were experienced as more marginalized, because of changes in the sharing of influence with people who formerly were almost without influence.
The project, with its first-person focus on people living with HIV at the expense of structurations that are constitutive in the processes of their disempowerment, may as such have contributed to their marginalization. The eventual support facility, although an opportunity for some people, certainly showed tendencies of this kind. The first turning point of the project, the decision of employing a researcher who would use a multiple-perspective method and a grounded methodology in researching the field, pointed in the direction of a project that would be democratic and encompass the perspectives and needs of future users. At the second turning point, the reception of the participant-oriented conclusion of the report made the implementation of a democratic project difficult. The third turning point, the appointment of members of the board of trusties, ended the development of a primarily democratic project and resulted in the implementation of a more bureaucratic facility. A tendency which, in many and intersecting ways, was related to societal processes in the field, such as the bureaucratization of medical and social support systems and the interests and perspectives developed through participating in them.

A noteworthy point is that contradictory contextual processes, personal perspectives and standpoints, goals and strategies also had complex consequences for the possible positions of the researcher, for the meanings of these positions, and for her methodological choices. These positions and choices needed to be mobile in order to obtain "dynamic objectivity" and as much knowledge as possible.

The related considerations were only partly included in the published report. Much of what is written here, and of what has been left out, would at the time obviously have created obstacles for the project as well as ethical problems. But this means that much knowledge that was and is relevant was not made accessible, which hampered the possibilities of working with dynamic objectivity. It raises the ques- 
tion of how it is possible to conceptualize excluded aspects of engendered knowledge without endangering participatory possibilities of individuals and of whole communities of practice.

Summing up, I want to emphasize that this text was not intended as a criticism of any single participants in the project or in the cooperation with it. Much rather, my intention has been to demonstrate how the perspectives and actions of individuals were, although personal, not simply individual. They were shaped as part of participating in and from different positions in institutions and other contexts such as NGOs. They were ways of dealing with the project that were co-determined by socio-political aspects of different positions of participation and the intersections of these.

In practice there are many situated and interrelating reasons for why we are rarely alert to the consequences this has for research. One is that it is a process of co-determination that is not easily noticeable; it is not directly identifiable and understandable in a given context. As such, it is mostly at play behind our backs. A second reason is the psychologisation (Alvarez-Uria 2004) of personal perspectives and interpersonal relations, which entails that we individualize complex historical and collective processes. A third reason is constituted by dominant discourses of the possible and necessary neutrality of research and researchers. This might engender blindness to the consequences of these processes for the development of a study, its conclusions and implicit recommendations.

Re-searching the HIV project illustrates how situated personal perspectives, standpoints, and strategies of participation contribute to choices of and developments in research practices. Presented conclusions and recommendations of a research report and the marginalization of others are not context-independent either. It is attempted to overcome this dependence by the instatement and use of rules and designs of the positivist paradigm. They are thought to insure the neutrality of researcher and research results. The same goes for the many research strategies which with kindred intentions borrow aspects of its methodology. They imply (intentional) de-contextualization and objectification of the research subject(s). It is rarely taken into consideration in reporting on studies. But from this follows that aspects of importance in the understanding of a field, such as the relations between intentionality of subjects involved and their conditions of participation, are excluded from research.

Research practices aiming at understanding the implications of the constitutional character of their subject(s) has to include such aspects instead of attempting to overcome them. In the HIV project, the possible meanings of the socio-political processes of double marginalization of many gay men, as gay and as patients, for the outcome of the project were partly disregarded. The possibilities of analysing the meanings of these and other relevant socio-political processes of power and marginalization, and of creating a democratically organized support facility, would have been greater, if from the start they had been more intentionally included in the study.

\section{References}

Axel, Erik (2002). Regulation as productive Tool Use. Roskilde University Press

Brown, Laura S. (1997). New Voices, New Visions: Toward a lesbian/gay paradigm for psychology. Gergen M. and Davis Sara: Toward a New Psychology of Gender. New York.

Alvarez-Uria, Fernando (2004). Journey to the interior of the self: the psycholisation of the self in a society of individuals. Journal of Critical Psychology Issue 12. Psychology and the Political. London.

Belenky, Mary Field, Clinchy Blythe McVicker, Golberger Nancy Rule, Tarule Jill Mattuck (1997). Women's ways of Knowing. The development of self voice and mind. New York. 
Danziger, Kurt (1990). Constructing the Subject. Cambridge.

Danziger, Kurt (1997). Naming the Mind. London.

Dreier, Ole (1996). Andring af professionel praksis på sundhedsområdet gennem praksisforskning. Aarhus.

Dreier, Ole (1997). Personal Locations and Perspectives. Aarhus.

Dreier, Ole (1999) Personal trajectories of Participation across Contexts of Social Practice, in Outlines 1, 5-32. Copenhagen.

Dreier, Ole (2002). Psykosocial behandling. En teori om et praksisområde. Copenhagen.

Ekeland, Tor-Johan (1999). Evidensbasert behandling: kvalitetssikring eller instrumentalistisk mistak. Tidsskrift for Norsk Psykologforening. Oslo.

Foote Whyte, William et al. (1991). Participatory Action Research, London.

Haavind, Hanne, red. (2000). Kjønn og fortolkende metode. Metodiske muligheder i kvalitativ forskning. Oslo.

Haavind, Hanne (1985). Forhold mellem kjønnene. Materialisten. Oslo.

Holzkamp, Klaus (1995). Alltägliche Lebensführung als subjektwissenschaftliches Grundkonzept. Das argument 37(6), 212, 817-846. Berlin,

Højholt, Charlotte (2001). Samarbejde om børns udvikling. Copenhagen. Jensen, Uffe Juul
(1983). Sygdomsbegreber i praksis. Copenhagen

Lave, Jean and Wenger, Etienne (1991). Situated Learning. Legitimate peripheral participation. Cambridge.

Martin, Jack F. (1996) The "Top Ten" Problems of Psychology. History and Philosophy of Psychology Bulletin Vol. 8,No 1. USA.

Montero, Maritza (2002). Ethics and politics in psychology. Twilight dimensions. Political Subjects. International Journal of Critical Psychology. Issue 6. Liverpool, UK.

Nissen, Morten (2000) Practice research - critical psychology in and through Practices. Annual Review of Critical Psychology. Action Research, no.2.

Nissen, Morten (1995). Forskningens betydning for udviklingen af psykosocial praksis. Udkast, 23,1, 4-33

Pedersen, Bodil (2001). Om kategoriseringer af køn og seksuelle relationer. Nordisk Udkast nr. $1,77-88$

Ronkainen, Suvi (1998). Inposssiblity of Reality and Possibility of the Survey as a Construction. Nordisk Udkast nr. 2, 26 årg, pp 51-62

Rokainen, Suvi (2001). Gendered Violence and Genderless Gender. A finnish Perspective. Kvinder, Kon og Forskning 2..

Steiner, Vera John (2000). Creative collaboration. Oxford. New York. 